\title{
Clothing Thermal Insulation for Typical Seasonal Clothing of Infant with Infant Thermal Manikin
}

\section{Yoshihito Kurazumi ${ }^{1}$, Kenta Fukagawa ${ }^{2}$, Tomonori Sakoi ${ }^{3}$, Akie Naito ${ }^{4}$, Motoe Imai ${ }^{5}$, Reiko Hashimoto ${ }^{1}$, Emi Kondo ${ }^{6}$, Tadahiro Tsuchikawa ${ }^{7}$}

${ }^{1}$ School of Life Studies, Sugiyama Jogakuen University, Nagoya, Japan

${ }^{2}$ Department of Architecture, Kyushu Sangyo University, Fukuoka, Japan

${ }^{3}$ Department of Advanced Textile and Kansei Engineering, Shinshu University, Ueda, Japan

${ }^{4}$ Institute for Global Leadership, Ochanomizu University, Tokyo, Japan

${ }^{5}$ Graduate School of Life Studies, Sugiyama Jogakuen University, Nagoya, Japan

${ }^{6}$ Department of Comprehensive Engineering, Kindai University Technical College, Nabari, Japan

${ }^{7}$ School of Human Science \& Environment, University of Hyogo, Himeji, Japan

Email:kurazumi@sugiyama-u.ac.jp

How to cite this paper: Kurazumi, Y., Fukagawa, K., Sakoi, T., Naito, A., Imai, M., Hashimoto, R., Kondo, E. and Tsuchikawa, T. (2021) Clothing Thermal Insulation for Typical Seasonal Clothing of Infant with Infant Thermal Manikin. Engineering, 13, 372-387.

https://doi.org/10.4236/eng.2021.137027

Received: June 3, 2021

Accepted: July 12, 2021

Published: July 15, 2021

Copyright $\odot 2021$ by author(s) and Scientific Research Publishing Inc. This work is licensed under the Creative Commons Attribution International License (CC BY 4.0).

http://creativecommons.org/licenses/by/4.0/

\begin{abstract}
Infants are less thermally adapted to their environment and can be considered as needing protective measures against thermal environments. It is not ethical to conduct subject experiments on infants. Thermal insulation in clothing is an essential control coefficient for the evaluation of the thermal environment of an infant. A thermal manikin can be used as an alternative method for carrying out experiments and to control the thermal manikin based on heat balance. The purpose of this study was to clarify the thermal insulation of infants' clothing. An infant thermal manikin was used to clarify the thermal insulation $\left(I_{c l}\right)$ of typical summer, mid-season, and winter clothing combinations for infants. The thermal insulation of typical seasonal clothing combinations was 0.30 clo for summer clothing, 0.57 clo for mid-season clothing and 1.02 clo for winter clothing. It was clarified that it is essential to consider clothing conditions by taking into account differences in posture and to define the clothing thermal insulation $\left(I_{c l}\right)$ when designing and evaluating thermal environments. When designing and evaluating an infant's thermal environment, it is essential to investigate using data from infants.
\end{abstract}

\section{Keywords}

Clothing Thermal Insulation, Infant, Posture, Season, Thermal Environment, Thermal Manikin 


\section{Introduction}

When planning and designing a thermal environment, design criteria values appropriate to the space are necessary. It is essential that the designed values of the thermal environment are standard numerical values that relate to the physical factors corresponding to thermal environment stimuli to the human physiological response to them. Although there are many physical factors, a thermal environment evaluation index derived from the heat balance of the human body, taking into account physiological and psychological temperature, is ordinarily used as a representative value for the environmental stimulus. Many of the components of these representative values are for the naked body. However, in a real space, people wear clothes, so it is necessary to conduct research on clothing.

Even if the thermal environment evaluation index is used as a representative value to design and evaluate the environment, coefficient values for the human body that constitute the thermal environment evaluation index and subject experiments, are required. However, it may be ethically unfeasible to conduct a human subject experiment on a particular group. In this case, a thermal manikin, which is a thermal model of the human body, is a useful experimental tool. Methods for controlling thermal manikins include constant surface temperature, constant heating value, and heat balance.

When considering the heat balance of the human body, the thermal effect of clothing is treated as a clothed heat transfer coefficient based on the naked body. Normally, clothing serves as an insulating layer between the human body and the surrounding environment and is treated as clothing thermal insulation. This clothing thermal insulation includes the thermal insulation of the layer of air that exists between the outer surface of the clothing and the skin surface. In a posture where the body surfaces are in contact with each other or the body surfaces are in contact with the surface of a chair or the floor, the layer of air in the space inside the clothing inevitably differs greatly from that for a non-contacting surface due to pressure, so it is necessary to understand the thermal insulation of the clothing according to posture. Hanada [1] [2], Olesen et al. [3], Nishimura et al. [4], Yamato et al. [5] [6], and Kurazumi et al. [7] clarified that different postures cause differences in clothing thermal insulation. Kurazumi et al. [8] [9] [10] clarified that, even if the physical thermal environment stimulus is the same, the numerical values of the thermal environment evaluation index differ when the posture is different. The clothing thermal insulation is affected by the heat transfer area of the clothing surface becoming greater than the skin surface. This could be due to the combination of clothing and differences in the way clothing is worn, such as folding and overlapping; and the layer of air between the skin surface and the clothing arising from the way in which the clothing is worn. Therefore, it is necessary to indicate the clothing thermal insulation assuming the posture in the space where the subject is.

The clothing thermal insulation can be obtained from the heat balance of the 
human body by either subject experiments [11] [12], or by using a thermal manikin [1]-[7] [13]-[25].

It is difficult to measure clothing thermal insulation every time a thermal environment is evaluated. Accordingly, the clothing thermal insulation for each typical garment [26] is indicated, or a formula for calculating the clothing thermal insulation is proposed [14] [16] [17] [19] [20] [24] [27].

However, previous studies of clothing thermal insulation have focused on adults; very few studies have focused on infants. An infant's body tends to warm up easily in a hot environment and cool down in a cold environment [28]. Therefore, infants are thought to have different adaptations to, and sensory perceptions of, their environment than adults [28] [29]. Compared to healthy individuals and adults, infants are less able to thermally adapt to their environment. The outdoor environment during the summer season is a severe environment from the perspective of body temperature regulation and it is considered necessary to take protective measures against the thermal environment. It is essential to take into account the difference in thermal effects on infants to those on adults, and so more care is needed.

It is not ethical to conduct experiments on infants regarding thermal environments based on heat balance. Therefore, to examine the thermal environment of infants, experiments and simulations using a human thermal model may be feasible by clarifying the human body coefficient values of infants. From this perspective, Kurazumi et al. [30] have developed a thermal manikin of an infant based on heat transfer area. Accumulation of human body coefficient values is indispensable for the control of an infant thermal manikin by heat balance. However, sufficient analysis and countermeasures are not yet apparent.

Focusing on the heat transfer area of infants, a reference surface area of the infant body has been measured [31]-[39]. Also, the solar radiation area factor of the infant body has been measured [40]. The clothing area factor of the infant body has also been measured [25] [41]. Research focusing on infants' clothing thermal insulation is limited to Fukazawa et al. [25] and is insufficient for studying the thermal environment of infants. In particular, it is difficult to say that sufficient research has been accumulated on infants' clothing thermal insulation. Therefore, in the absence of basic data for infants, it is essential to clarify the clothing thermal insulation by actual measurements.

The heat balance of the human body is incorporated into the human body's evaluation of thermal environments; clothing thermal insulation is an essential control element for the evaluation of an infant's thermal environment using a thermal manikin and control of the thermal manikin based on the heat balance of the human infant body. Therefore, the purpose of this study was to clarify infants' clothing thermal insulation.

\section{Experimental Plan}

We conducted an experiment to clarify the thermal insulation of infants' clothing by actual measurements, according to the combination of clothing in typical 
seasons. The clothing thermal insulation was calculated using the calculation method of Kurazumi et al. [7], based on the theory of Seppanenn et al. [13]. The clothing thermal insulation $\left(I_{c l}\right)$ can be expressed by the following equation.

$$
\begin{gathered}
I_{a}=\left(t_{s}-t_{o}\right) / 0.155 Q_{a} \\
I_{t}=\left(t_{c l}-t_{o}\right) / 0.155 Q_{t} \\
I_{c l}=I_{t}-I_{a} / f_{c l} \\
f_{c l}=A_{c l} / A_{s}
\end{gathered}
$$

Here,

$I_{a}$ : Thermal insulation in the naked state [clo]

$I_{i}$ : Thermal insulation in the clothed state [clo]

$I_{c i}$. Clothing thermal insulation [clo]

$Q_{a}:$ Heat loss from naked infant thermal manikin $\left[\mathrm{W} / \mathrm{m}^{2}\right]$

$Q_{i}$. Heat loss from clothed infant thermal manikin $\left[\mathrm{W} / \mathrm{m}^{2}\right]$

$t_{s}$ : Body surface temperature $\left[{ }^{\circ} \mathrm{C}\right]$

$t_{c i}$ Outer clothing surface temperature $\left[{ }^{\circ} \mathrm{C}\right]$

$t_{o}$ : Operative temperature $\left[{ }^{\circ} \mathrm{C}\right]$

$A_{c l}$ Outer surface area of clothed infant thermal manikin $\left[\mathrm{m}^{2}\right]$

$A_{s}$ : Body surface area of naked infant thermal manikin $\left[\mathrm{m}^{2}\right]$

$f_{c i}$ Clothing area factor [N.D.].

The experiment was carried out in the environmental laboratory shown in Figure 1. The environmental laboratory was equipped with a conventional air-conditioning system, with air intake and exhaust being conducted from the wall. The walls and ceilings were covered with thin curtains to give thermal environmental conditions such that the mean radiant temperature was homogeneous with the air temperature.

The subject of the measurements should be a healthy infant but this is not ethically possible. Therefore, the experiment was conducted using the infant thermal manikin of Kurazumi et al. [30], which was developed to mimic the human infant model "Nurse Training Baby" [42] used in the measurement of clothing area factor in Kurazumi et al. [41]. Figure 2 shows the infant thermal manikin. Table 1 shows the characteristics of the infant thermal manikin.

The height of the human infant model used in this study [30] was about 50 $60 \mathrm{~cm}$. From the Growth Survey of Infants of the Ministry of Health, Labour and Welfare of Japan [43], the 50th percentile data for the age of 1 to 2 months was extracted, giving a height of $55.6 \mathrm{~cm}$ and weight of $4.79 \mathrm{~kg}$. Comparing the body surface area calculated from this height and weight data [32] [33] [34] [36] [44] [45] [46] with the measured body surface area of the infant thermal manikin of Kurazumi et al. [30], clarified the validity of the infant thermal manikin dimensions. Table 1 shows the body surface area of the infant thermal manikin [30].

The clothing used in the experiment was the same typical seasonal clothing combination as in the measurement of the clothing area factor in Kurazumi et al. [41]. The combinations of infant clothing by season are shown in Figure 3. Table 2 shows the characteristics of the clothing. When dressing the infant thermal 
manikin, sufficient care was taken to avoid uneven distribution of folds and overlaps due to wrinkles on the surface. The wrinkles, folds and overlaps of the clothing that occur when the infant thermal manikin was moved to the set posture were assumed to be natural.

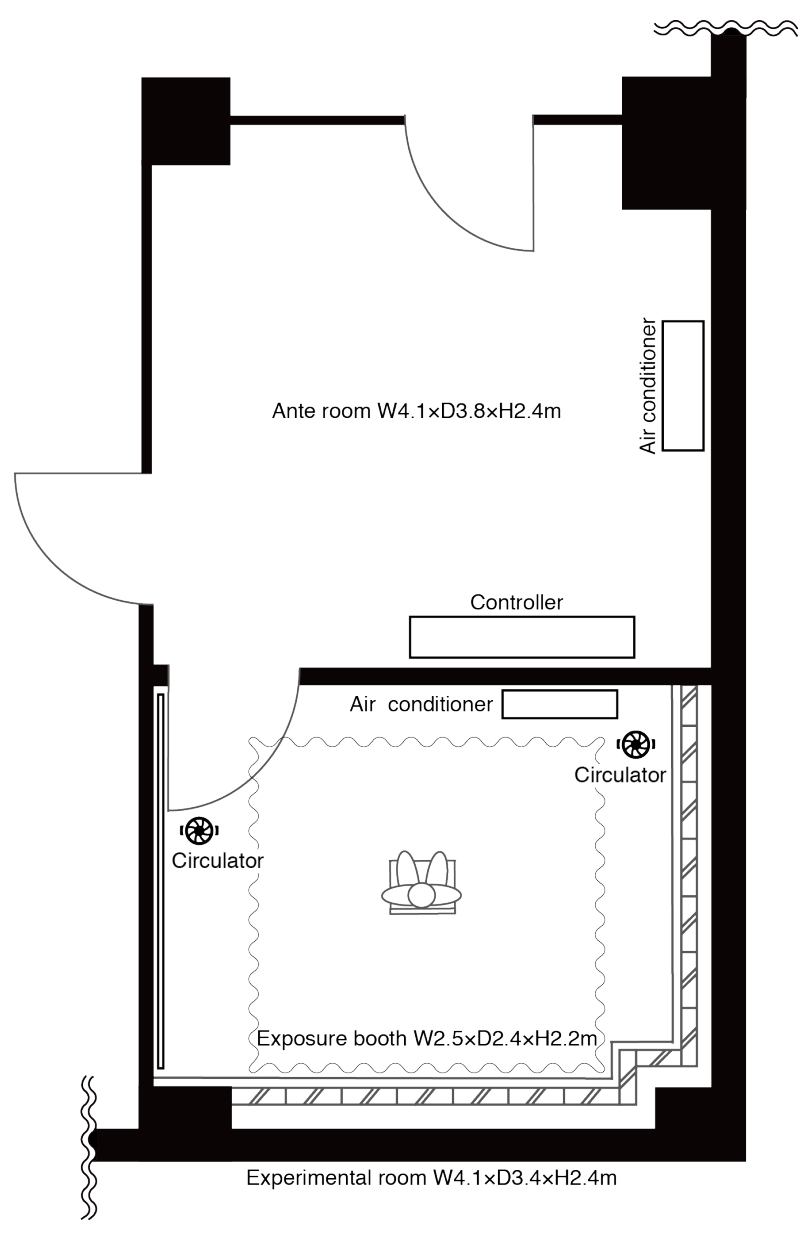

Figure 1. Plan of experimental setup where infant thermal manikin is exposed to thermal conditions.

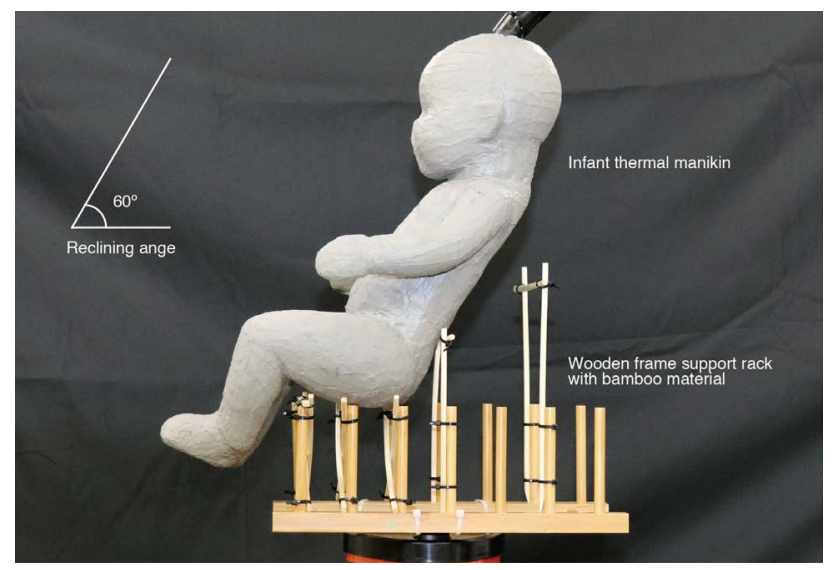

Figure 2. Infant thermal manikin. Posture is sitting on wooden frame support rack with bamboo material. Recline angle is $60^{\circ}$. 

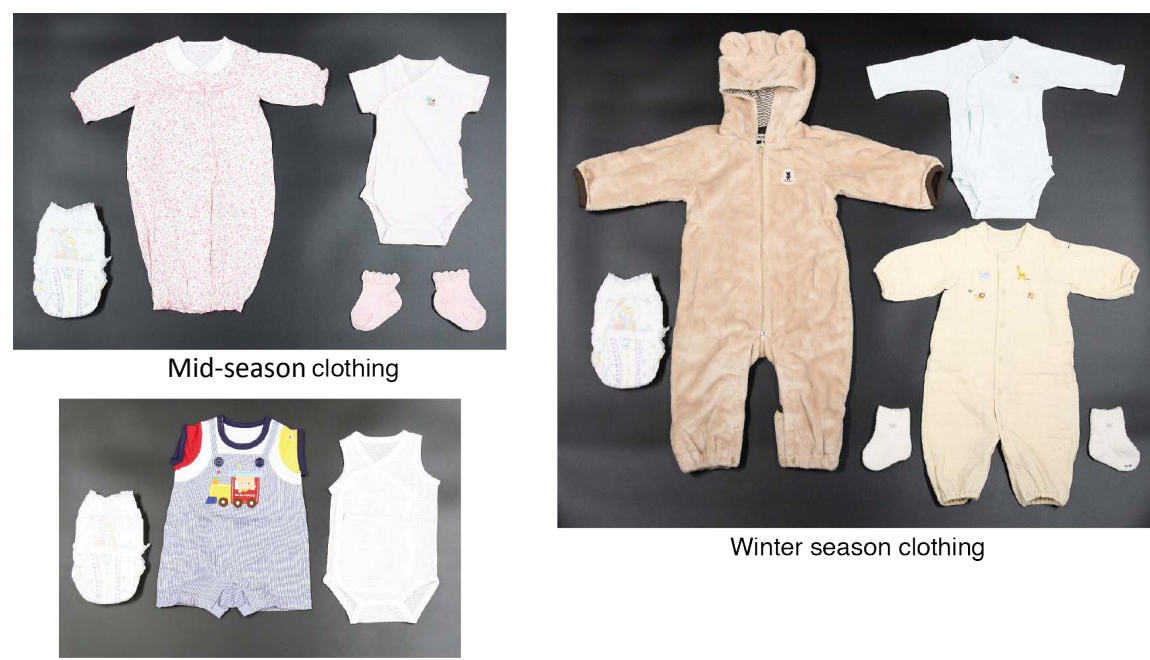

Winter season clothing

Summer season clothing

Figure 3. Seasonal clothing ensembles.

Table 1. Characteristics of infant thermal manikin.

\begin{tabular}{|c|c|c|c|c|c|}
\hline Region & Surface area $\left[\mathrm{cm}^{2}\right]$ & Area ratio [-] & Area ratio $[-]$ & Area ratio [-] & Area ratio [-] \\
\hline Anterior head & 352.99 & 0.157 & 0.240 & 0.240 & 0.240 \\
\hline Posterior head & 187.97 & 0.083 & & & \\
\hline Ventral trunk & 316.41 & 0.141 & 0.285 & 0.285 & 0.285 \\
\hline Dorsal trunk & 324.69 & 0.144 & & & \\
\hline Right medial arm & 54.39 & 0.024 & 0.060 & 0.120 & 0.159 \\
\hline Right lateral arm & 79.88 & 0.036 & & & \\
\hline Left medial arm & 54.48 & 0.024 & 0.060 & & \\
\hline Left lateral arm & 81.67 & 0.036 & & & \\
\hline Right dorsal hand & 24.60 & 0.011 & 0.020 & 0.039 & \\
\hline Right palmar hand & 19.51 & 0.009 & & & \\
\hline Left dorsal hand & 23.80 & 0.011 & 0.019 & & \\
\hline Left palmar hand & 18.99 & 0.008 & & & \\
\hline Right anterior leg & 158.52 & 0.070 & 0.128 & 0.258 & 0.316 \\
\hline Right posterior leg & 131.23 & 0.058 & & & \\
\hline Left anterior leg & 155.25 & 0.069 & 0.130 & & \\
\hline Left posterior leg & 136.64 & 0.061 & & & \\
\hline Right dorsal foot & 32.57 & 0.015 & 0.030 & 0.058 & \\
\hline Right planter foot & 34.75 & 0.015 & & & \\
\hline Left dorsal foot & 30.23 & 0.013 & 0.028 & & \\
\hline Left planter foot & 34.22 & 0.015 & & & \\
\hline
\end{tabular}


Table 2. Characteristics of seasonal clothing ensembles.

\begin{tabular}{|c|c|c|c|c|}
\hline Description & Detail & Material (\%) & Weight (g) & Remark \\
\hline \multicolumn{5}{|l|}{ Summer season } \\
\hline Diaper & & & 25 & Pampers swaddlers, 0 - 3 months \\
\hline Underwear & Sleeveless rompers & Mesh Tenjik cotton (100) & 31 & miki house, 0 - 3 months, $60 \mathrm{~cm}$ \\
\hline Short coverall & Short sleeve T-shirt and rompers & Cotton (100) & 73 & miki house, $0-3$ months, $60 \mathrm{~cm}$ \\
\hline \multicolumn{5}{|l|}{ Mid-season } \\
\hline Diaper & & & 25 & Pampers swaddlers, 0 - 3 months \\
\hline Underwear & Short sleeve rompers & Milling cotton (100) & 43 & miki house, 0 - 3 months, $60 \mathrm{~cm}$ \\
\hline Two-way coverall & Long sleeve rompers & Cotton (100) & 92 & miki house, 0 - 3 months, $50-60 \mathrm{~cm}$ \\
\hline \multirow[t]{3}{*}{ Socks } & & Cotton (83) & 13 & miki house, 0 - 3 months, $9-10 \mathrm{~cm}$ \\
\hline & & Nylon (16) & & \\
\hline & & Polyurethane (1) & & \\
\hline \multicolumn{5}{|l|}{ Winter season } \\
\hline Diaper & & & 25 & Pampers swaddlers, 0 - 3 months \\
\hline Underwear & Long sleeve rompers & Milling cotton (100) & 48 & miki house, 0 - 3 months, $60 \mathrm{~cm}$ \\
\hline Two-way coverall & Long sleeve rompers & Cotton (100) & 133 & miki house, 0 - 3 months, $50-60 \mathrm{~cm}$ \\
\hline \multirow[t]{2}{*}{ Coverall } & Long sleeve rompers & Front fablic: polyester (100) & 431 & miki house, 0 - 3 months, $60-80 \mathrm{~cm}$ \\
\hline & & Back fablic: Cotton (100) & & \\
\hline \multirow[t]{4}{*}{ Socks } & & Acrylic (75) & 19 & miki house, 0 - 3 months, $9-10 \mathrm{~cm}$ \\
\hline & & Polyester (18) & & \\
\hline & & Nylon (5) & & \\
\hline & & Polyurethane (2) & & \\
\hline
\end{tabular}

The experiment was carried out with the manikin in the posture shown in Figure 2. The set posture was the same as in the measurement of the clothing area factor by Kurazumi et al. [41]. It has been verified that the infant thermal manikin [30] and the human infant model [42] used by Kurazumi et al. [41] can be regarded as identical, in terms of geometry and heat transfer area [30]. Therefore, it is considered possible to use the infant's clothing area factor [41] according to typical seasonal clothing combinations for the clothing area factor that is essential for the calculation of the clothing thermal insulation.

To maintain the posture, the infant thermal manikin was positioned directly on a wooden frame with good air permeability and a support made of $5 \mathrm{~mm}$ bamboo material, $0.9 \mathrm{~m}$ above the floor in the exposure space. All surfaces of the manikin were open to the airflow, except for those that were in contact with each other. The surface of the thermal manikin was considered to be open to the atmosphere because the support rack had a small heat capacity and few parts were in contact with the infant thermal manikin.

Kurazumi et al. [7] clarified that clothing thermal insulation is affected by 
posture and air temperature. This study is positioned as a basic exploratory study to clarify the typical clothing thermal insulation of an infant. Table 3 shows the set thermal environment conditions. The thermal environment conditions were homogeneous, such that the mean radiant temperature was homogeneous with the air temperature at three different temperatures: $20^{\circ} \mathrm{C}, 22^{\circ} \mathrm{C}$ and $24^{\circ} \mathrm{C}$. Air velocity (a still condition of current under $0.2 \mathrm{~m} / \mathrm{s}$ ) and relative humidity $(60 \% \mathrm{RH})$ were constant for all conditions.

The thermal environment parameters measured were air temperature, humidity, vertical temperature distribution, air velocity, and temperature of each surface of the exposure space. Air temperature and humidity were measured with an Assmann ventilated psychrometer, air velocity with a non-directional hot-bulb anemometer, and vertical temperature distribution and surface temperature of each surface in the exposure space with a $0.2 \mathrm{~mm} \varphi$ T-type thermocouple with a measurement interval of 5 seconds. Vertical temperature distributions were measured at heights of $0.0,0.1,0.3,0.6,0.9,1.2,1.5,1.7,2.0$ and $2.2 \mathrm{~m}$ above the floor surface.

The surface temperature and heat loss were measured as the conditions on the infant thermal manikin side. For surface temperature and heat loss, power consumption was measured at a measurement interval of 5 seconds. The set thermal environment was maintained for at least 2 hours to ensure that the exposure space was in a steady state. The power level of the thermal manikin was then controlled to keep the surface temperature constant for more than 1 hour, such that it could reach a steady state. ISO 9920 [27] specifies an average skin temperature of $32^{\circ} \mathrm{C}-34^{\circ} \mathrm{C}$ for thermal manikins as the experimental condition for clo value. Oketani and Tokura [47] found that the skin temperature of infants is higher than that of adults. The skin thickness of infants is a half to a third of that of adults [48], so the skin temperature of infants is higher. Therefore, the surface temperature of the infant thermal manikin was set to $34^{\circ} \mathrm{C}$.

Table 3. Experimental conditions.

\begin{tabular}{|c|c|c|c|c|}
\hline Clothing & Air Temperature $\left[{ }^{\circ} \mathrm{C}\right]: \mathrm{T}_{\mathrm{a}}$ & Air Velocity $[\mathrm{m} / \mathrm{s}]: \mathrm{V}_{\mathrm{a}}$ & Ralative Humidity [\%]: RH & Mean Radiant Temperature $\left[{ }^{\circ} \mathrm{C}\right]: \mathrm{MRT}$ \\
\hline Naked & 20.0 & & & \\
\hline Naked & 22.0 & & & \\
\hline Naked & 24.0 & & & \\
\hline Summer & 20.0 & & & \\
\hline Summer & 22.0 & & & \\
\hline Summer & 24.0 & $<0.2$ & $=50$ & $=\mathrm{Ta}$ \\
\hline Mid-season & 20.0 & & & \\
\hline Mid-season & 22.0 & & & \\
\hline Mid-season & 24.0 & & & \\
\hline Winter & 20.0 & & & \\
\hline Winter & 22.0 & & & \\
\hline Winter & 24.0 & & & \\
\hline
\end{tabular}


After confirming that thermal equilibrium was established between the infant thermal manikin and the ambient environment, and that the set thermal environmental conditions and the heat loss from the infant thermal manikin were in a steady state, the infant thermal manikin was exposed to the set thermal environmental conditions for 70 minutes. The 60 minutes of data from 5 minutes after the start of the experiment to 5 minutes before the end, was used in the analysis.

In this study, the significance probability was 5\%. JMP 14.3 (SAS Institute Japan) was used for statistical analysis.

\section{Results and Discussion}

Before Table 4 shows the measurement results for the thermal environment conditions. The temperature for each experimental condition was controlled within a range of $\pm 0.1^{\circ} \mathrm{C}$, with a deviation of about $0.2^{\circ} \mathrm{C}$. Relative humidity was controlled within a range of $\pm 1.5 \%$ and with a deviation of about $8 \%$. Although the surface temperature of the surrounding wall surfaces had a difference of about $1^{\circ} \mathrm{C}$ from the floor surface temperature, it was almost identical to the air temperature. Since the angle factor of the infant is not known, it is not possible to determine an exact mean radiant temperature, but the surface area-weighted mean radiant temperature was almost identical to the air temperature. Figure 4 shows the vertical air temperature distribution, including air temperature and floor/ceiling surface temperature. The air temperature range was within $1^{\circ} \mathrm{C}$. Air velocity was under $0.2 \mathrm{~m} / \mathrm{s}$ throughout the experiment. The thermal environment during each experiment generally satisfied the set conditions. ISO 9920 [27] states that the experimental conditions for the clo value are the difference between the air temperature and the mean radiant temperature within $5^{\circ} \mathrm{C}$, where air velocity is a calm airflow, and relative humidity is from $10 \%$ to $70 \%$ with no variation during the experiment. Therefore, it can be said that the validity of calculating the clothing thermal insulation by the results of this experiment was verified.

Table 4. Results of thermal conditions.

\begin{tabular}{|c|c|c|c|c|c|c|c|}
\hline Clothing & $\begin{array}{c}\text { Air } \\
\text { Temperature }\left[{ }^{\circ} \mathrm{C}\right]: \\
\mathrm{T}_{\mathrm{a}}\end{array}$ & $\begin{array}{c}\text { Air Velocity } \\
{[\mathrm{m} / \mathrm{s}]: \mathrm{V}_{\mathrm{a}}}\end{array}$ & $\begin{array}{c}\text { Ralative } \\
\text { Humidity [\%]: } \\
\text { RH }\end{array}$ & $\begin{array}{c}\text { Floor } \\
\text { Temperature }\left[{ }^{\circ} \mathrm{C}\right] \text { : } \\
\mathrm{T}_{\mathrm{f}}\end{array}$ & $\begin{array}{c}\text { Wall } \\
\text { Temperature }\left[{ }^{\circ} \mathrm{C}\right]: \\
\mathrm{T}_{\mathrm{w}}\end{array}$ & $\begin{array}{c}\text { Ceiling } \\
\text { Temperature }\left[{ }^{\circ} \mathrm{C}\right] \text { : } \\
\mathrm{T}_{\mathrm{c}}\end{array}$ & $\begin{array}{c}\text { Mean Radiant } \\
\text { Temperature }\left[{ }^{\circ} \mathrm{C}\right]: \\
\text { MRT }\end{array}$ \\
\hline Naked & $20.14 \pm 0.05$ & $0.03 \pm 0.02$ & $52.89 \pm 0.45$ & $19.70 \pm 0.03$ & $20.28 \pm 0.05$ & $19.95 \pm 0.05$ & $20.12 \pm 0.03$ \\
\hline Naked & $22.12 \pm 0.06$ & $0.05 \pm 0.04$ & $53.67 \pm 0.61$ & $21.24 \pm 0.05$ & $22.26 \pm 0.07$ & $22.15 \pm 0.07$ & $22.06 \pm 0.06$ \\
\hline Naked & $24.16 \pm 0.08$ & $0.03 \pm 0.03$ & $57.57 \pm 0.84$ & $23.10 \pm 0.05$ & $24.30 \pm 0.07$ & $24.71 \pm 0.17$ & $24.16 \pm 0.09$ \\
\hline Summer & $20.01 \pm 0.06$ & $0.02 \pm 0.02$ & $54.29 \pm 0.55$ & $19.39 \pm 0.05$ & $20.22 \pm 0.05$ & $19.79 \pm 0.04$ & $19.99 \pm 0.05$ \\
\hline Summer & $22.06 \pm 0.07$ & $0.03 \pm 0.02$ & $53.69 \pm 0.38$ & $21.53 \pm 0.07$ & $22.14 \pm 0.08$ & $21.94 \pm 0.06$ & $22.00 \pm 0.07$ \\
\hline Summer & $24.14 \pm 0.05$ & $0.02 \pm 0.02$ & $56.10 \pm 0.70$ & $22.89 \pm 0.06$ & $24.24 \pm 0.06$ & $24.15 \pm 0.09$ & $23.98 \pm 0.07$ \\
\hline Mid-season & $20.11 \pm 0.05$ & $0.03 \pm 0.03$ & $54.16 \pm 0.97$ & $19.31 \pm 0.06$ & $20.16 \pm 0.05$ & $19.84 \pm 0.06$ & $19.95 \pm 0.06$ \\
\hline Mid-season & $22.04 \pm 0.05$ & $0.03 \pm 0.02$ & $48.76 \pm 1.15$ & $21.03 \pm 0.09$ & $22.10 \pm 0.05$ & $21.97 \pm 0.05$ & $21.89 \pm 0.06$ \\
\hline Mid-season & $24.13 \pm 0.07$ & $0.03 \pm 0.03$ & $47.83 \pm 0.69$ & $23.05 \pm 0.19$ & $24.22 \pm 0.09$ & $24.14 \pm 0.10$ & $24.00 \pm 0.11$ \\
\hline Winter & $19.98 \pm 0.07$ & $0.03 \pm 0.03$ & $55.73 \pm 0.62$ & $19.61 \pm 0.09$ & $20.09 \pm 0.07$ & $19.78 \pm 0.06$ & $19.95 \pm 0.07$ \\
\hline Winter & $22.13 \pm 0.05$ & $0.03 \pm 0.02$ & $57.93 \pm 0.54$ & $21.40 \pm 0.06$ & $22.24 \pm 0.05$ & $22.04 \pm 0.05$ & $22.05 \pm 0.05$ \\
\hline Winter & $24.15 \pm 0.05$ & $0.02 \pm 0.02$ & $54.72 \pm 1.30$ & $23.06 \pm 0.09$ & $24.16 \pm 0.07$ & $24.08 \pm 0.05$ & $23.95 \pm 0.07$ \\
\hline
\end{tabular}




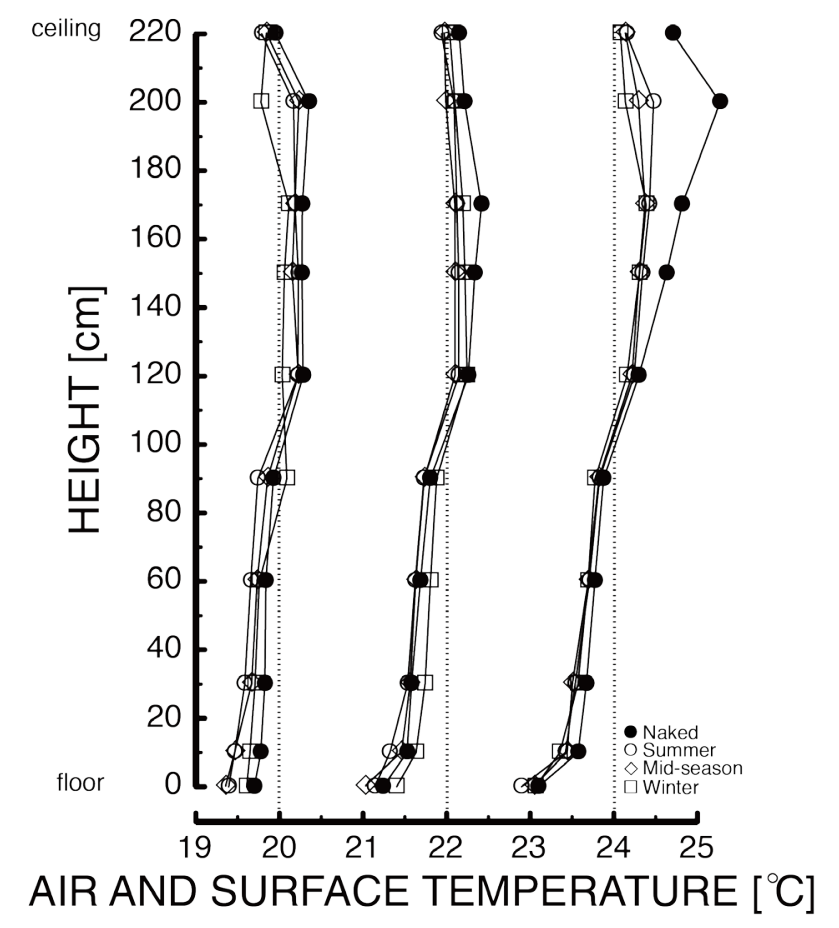

Figure 4. Distribution of vertical air and surface temperature in exposure space.

The thermal insulation in the naked state $\left(I_{a}\right)$, thermal insulation in the clothed state $\left(I_{t}\right)$ and clothing thermal insulation $\left(I_{c l}\right)$ are shown in Figure 5. The thermal insulation in the naked state $\left(I_{a}\right)$ was 0.51 clo when the operative temperature was $20.14^{\circ} \mathrm{C}$. At $22.12^{\circ} \mathrm{C}$, it was 0.50 clo. At $24.16^{\circ} \mathrm{C}$, it was 0.51 clo. No significant differences in operative temperature were observed. Kurazumi et al. [7] found that the higher the operative temperature, the smaller the difference with the surface temperature of the thermal manikin, which has the effect of reducing the driving force of natural convection. In other words, they found that when the natural convection driving force is reduced, the updraft flow along the surface of the thermal manikin slows and the thermal boundary layer becomes thicker. However, in the temperature range of this study, no temperature dependence was observed in thermal insulation in the naked state. The significance of the regression coefficients of the regression equation was tested by ANOVA $(\mathrm{p}=0.73)$ and the result was $\mathrm{p}>0.05$, so the slope of the regression equation was judged not to be valid. Therefore, the thermal insulation of the naked body $\left(I_{a}\right)$ can be expressed by an average value of 0.51 clo.

The thermal insulation in the clothed state $\left(I_{t}\right)$ was 0.72 clo when the operative temperature of summer clothing was $20.01^{\circ} \mathrm{C}$. At $22.06^{\circ} \mathrm{C}$, it was 0.71 clo. At $24.14^{\circ} \mathrm{C}$, it was $0.73 \mathrm{clo}$. No significant differences in operative temperature were observed. As in the case of the naked body, the results showed no temperature dependence on thermal insulation in the clothed state $\left(I_{t}\right)$. The significance of the regression coefficients of the regression equation was tested by ANOVA ( $\mathrm{p}=$ 0.42 ) and the result was $p>0.05$, so the slope of the regression equation was 


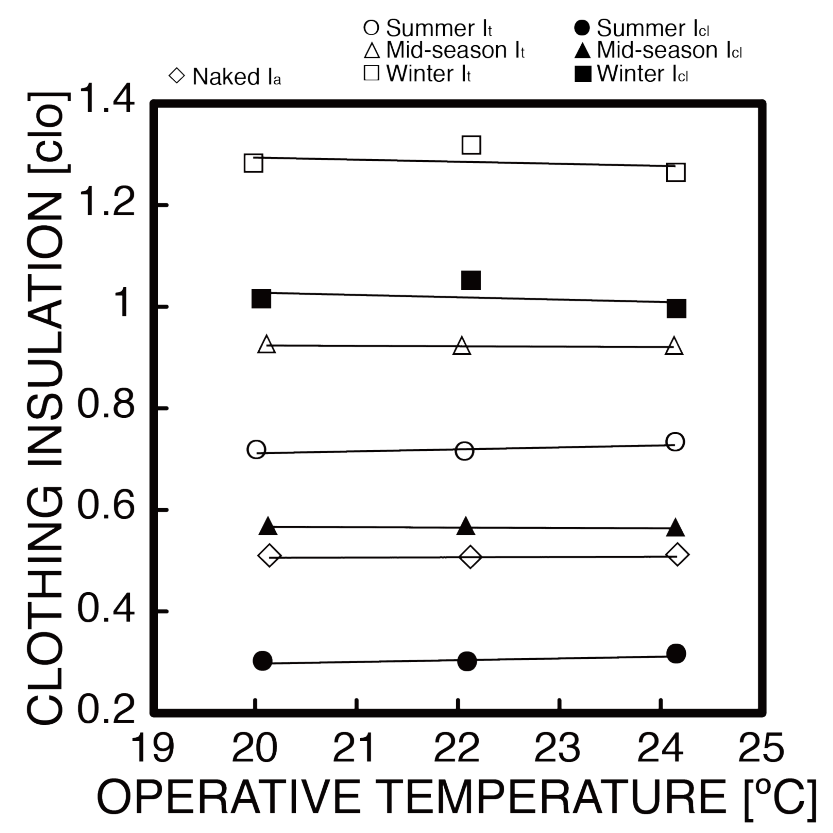

Figure 5. Relation between operative temperature and thermal insulation. $I_{a}$ is thermal insulation of naked infant thermal manikin. $I_{t}$ is thermal insulation of clothed infant thermal manikin. $I_{c l}$ is clothing thermal insulation.

judged not to be valid. Therefore, the thermal insulation of the clothed body $\left(I_{t}\right)$ can be expressed as an average value of 0.72 clo. This was 0.92 clo when the operative temperature of mid-season clothing was $20.10^{\circ} \mathrm{C}$. At $22.04^{\circ} \mathrm{C}$, it was 0.92 clo. At $24.13^{\circ} \mathrm{C}$, it was 0.92 clo. No significant differences in operative temperature were observed. As in the case of the naked body, the results showed no temperature dependence on thermal insulation in the clothed state $\left(I_{t}\right)$. The significance of the regression coefficients of the regression equation was tested by ANOVA $(\mathrm{p}=0.35)$ and the result was $\mathrm{p}>0.05$, so the slope of the regression equation was judged not to be valid. Therefore, the thermal insulation of the clothed body $\left(I_{t}\right)$ can be expressed by an average value of 0.92 clo. This was 1.28 clo when the operative temperature of winter clothing was $19.98^{\circ} \mathrm{C}$. At $22.13^{\circ} \mathrm{C}$, it was 1.32 clo. At $24.15^{\circ} \mathrm{C}$, it was 1.26 clo. No significant differences in operative temperature were observed. As in the case of the naked body, the results showed no temperature dependence on thermal insulation in the clothed state $\left(I_{t}\right)$. The significance of the regression coefficient of the regression equation was tested by ANOVA $(p=0.80)$ and the result was $p>0.05$, so the slope of the regression equation was judged not to be valid. Therefore, the thermal insulation of the clothed body $\left(I_{t}\right)$ can be expressed by an average value of 1.29 clo.

The clothing thermal insulation $\left(I_{c l}\right)$ was 0.30 clo when the operative temperature of summer clothing was $20.07^{\circ} \mathrm{C}$. At $22.09^{\circ} \mathrm{C}$, it was $0.30 \mathrm{clo}$. At $24.15^{\circ} \mathrm{C}$, it was 0.31 clo. No significant differences in operative temperature were observed. This was 0.57 clo when the operative temperature of mid-season clothing was $20.12^{\circ} \mathrm{C}$. At $22.08^{\circ} \mathrm{C}$, it was 0.57 clo. At $24.14^{\circ} \mathrm{C}$, it was 0.56 clo. No significant 
differences in operative temperature were observed. This was 1.12 clo when the operative temperature of winter clothing was $20.06^{\circ} \mathrm{C}$. At $22.12^{\circ} \mathrm{C}$, it was 1.05 clo. At $24.15^{\circ} \mathrm{C}$, it was 0.99 clo. No significant differences in operative temperature were observed. No temperature dependence was observed for any of the clothing conditions. The significance of the regression coefficient of the regression equation for clothing thermal insulation $\left(I_{c l}\right)$ was tested by ANOVA and the result was $\mathrm{p}=0.37$ for summer clothing, $\mathrm{p}=0.22$ for mid-season clothing, and $\mathrm{p}$ $=0.79$ for winter clothing. All were $\mathrm{p}>0.05$, so the slope of the regression equation was judged not to be valid. Therefore, the clothing thermal insulation $\left(I_{c l}\right)$ was 0.30 for summer clothing, 0.57 for mid-season clothing, and 1.02 for winter clothing.

Experiments on the clothing thermal insulation $\left(I_{c l}\right)$ using a thermal manikin require accurate determination of the temperature of the outer surface of the clothing and consideration of the fact that the temperature of the outer surface of the clothing is lower than the surface temperature of the naked body. However, within the scope of this study, the difference between naked body surface thermal insulation and clothing outer surface thermal insulation cannot be accurately determined. In order to obtain the true value of the physical clothing thermal insulation in an experiment using a thermal manikin, it is essential to accurately determine the temperature of the outer surface of the clothing. However, in this study, it was judged to be possible to examine the difference of clothing within a certain range by relative comparison of clothing thermal insulation $\left(I_{c l}\right)$ without examining the difference between naked body surface thermal insulation and clothing outer surface thermal insulation, because the thermal environmental conditions were exactly the same.

In an example of experimental research attempting to clarify the clothing thermal insulation $\left(I_{c l}\right)$ of infants aged 0 - 12 months, Fukazawa et al. [25] used a thermal manikin in a standing position for infants aged 6 - 12 months. In Fukazawa et al. [25], clothing thermal insulation for the summer combination of short sleeves with T-shirt and short trousers was 0.46 clo. Clothing thermal insulation $\left(I_{c l}\right)$ for the mid-season combination of undershirt with socks, sweatshirt, and thin trousers was 0.52 clo. Clothing thermal insulation $\left(I_{c l}\right)$ for the winter combination of undershirt with socks, long sleeve shirt, vest, jumper, and thick trousers was 2.22 clo. Fukazawa et al. [25] planned an experiment with a combination of clothing according to the study region but considered the clothing condition to be excessive. The infant's clothing thermal insulation $\left(I_{c l}\right)$ in this study does not differ significantly from the summer and mid-season clothing thermal insulation $\left(I_{c l}\right)$ of Fukazawa et al. [25], but a significant difference is observed for winter clothing. The winter clothing combination in Fukazawa et al. [25] consisted of about one more outer garment compared to that of this study. As Kurazumi et al. [41] pointed out, there may be an effect of the markedly smaller clothing area factor $\left(f_{c l}\right)$ of the clothing used in the study by Fukazawa et al. [25]. In addition, differences in posture and the degree of fit of the clothing may have an effect. Olesen et al. [3] and Nishimura et al. [4], who studied adults, 
found that the clothing thermal insulation $\left(I_{c c}\right)$ in a chair-seated position was about $15 \%$ lower than that in a standing position. Similarly, Kurazumi et al. [7], who studied adults, found the reduction to be around $28 \%$. In other words, although there are differences in the material of the clothing and the clothing combinations, it can be inferred that posture also has a pronounced influence. Therefore, when designing and evaluating thermal environments, it is essential to consider clothing conditions, taking into account differences in posture, and to define the clothing thermal insulation $\left(I_{c l}\right)$.

Normally, infant's clothing is considered to be slightly large and to have a lot of ease. The seasonal clothing determined in this study is useful data for examining the thermal environment of infants.

\section{Conclusions}

It is not ethical to conduct experiments on infants regarding thermal environments based on heat balance. Therefore, experiments and simulations using a human thermal model may be feasible by clarifying the human body coefficient values of infants. Moreover, accumulation of human body coefficient values is indispensable for the control of an infant thermal manikin by heat balance. In this study, for the purpose of clarifying the clothing thermal insulation $\left(I_{c l}\right)$ of a typical combination of clothing for infants, the clothing thermal insulation $\left(I_{c l}\right)$ of summer, mid-season and winter clothing was measured using an infant thermal manikin. The clothing thermal insulation $\left(I_{c l}\right)$ of typical clothing combinations for each season was 0.30 clo for summer clothing, 0.57 clo for mid-season clothing and 1.02 clo for winter clothing. This study clarified that it is essential to consider clothing conditions by taking into account differences in posture and to define clothing thermal insulation $\left(I_{c l}\right)$ when designing and evaluating thermal environments. When designing and evaluating an infant's thermal environment, it is essential to investigate using data from infants.

The results of this research can be utilized in the development of clothing for infants. And it contributes to the universal design of the thermal environment plan.

\section{Acknowledgements}

We would like to express our sincere gratitude to those who participated in this research. This work was supported by JSPS KAKENHI Grant Number JP18H01594.

\section{Conflicts of Interest}

The authors declare no conflicts of interest regarding the publication of this paper.

\section{References}

[1] Hanada, K. (1979) Studies on the Regional Thermal Resistance of Clothing System Part 1: On Sportswear. Journal of the Japan Research Association for Textile End-Use, 20, 273-279. 
[2] Hanada, K. (1979) Studies on the Regional Thermal Resistance of Clothing System Part 2: One-Piece Dresses. Journal of the Japan Research Association for Textile End-Use, 20, 305-310.

[3] Olesen, B.W., Silwinska, E., Madsen, T.L. and Fanger, P.O. (1982) Effect of Body Posture and Activity on the Thermal Insulation of Clothing; Measurements by a Movable Thermal Manikin. ASHRAE Transactions, 88, 791-805.

[4] Nishimura, M., Tanabe, S. and Hasebe, Y. (1994) Thermal Insulation of Clothing for Seated and Standing Postures. The Annals of Physiological Anthropology, 13, 337-343. https://doi.org/10.2114/ahs1983.13.337

[5] Yamato, Y., Kurazumi, Y., Hashida, M., Torii, T. and Matsubara, N. (2003) Difference of Postures on Thermal Insulation of Clothing Ensembles. Journal of Human and Living Environment, 10, 108-116.

[6] Yamato, Y., Kurazumi, Y., Ishii, J., Fukagawa, K., Tobita, K., Matsubara, N. and Shibata, Y. (2010) The Influence of Extra Space of Clothing for Human Body on Thermal Insulation of Clothing Ensembles, Experimental Study on Woman's Clothes. Journal of the Japan Research Association for Textile End-Uses, 51, 281-292.

[7] Kurazumi, Y., Horiguchi, A., Sakamoto, H. and Matsubara, N. (2006) The Influence of Postures on Thermal Insulation of Clothing. Journal of Environmental Engineering (Transactions of AI), 605, 63-70. https://doi.org/10.3130/aije.71.63_3

[8] Kurazumi, Y., Matsubara, N., Narumi, D., Nagano, K., Tsuchikawa, T. and Horikoshi, T. (1998) The Influence of Posture upon Sensible Temperature. Japanese Journal of Biometeorology, 35, 35-44.

[9] Kurazumi, Y., Matsubara, N., Nagai, H., Furukawa, N., Fujiwara, M., Ue, A., Ueki, Y. and Yamamoto, S. (1999) The Effect of Conductive Heat Exchange for Evaluation of the Thermal Environment on the Human Body. Transactions of the Society of Heationg, Air-Conditioning and Sanitary Engineers of Japan, 72, 25-36.

[10] Kurazumi, Y., Matsubara, N., Ueki, Y., Ue, A., Nagai, H., Yamamoto, S., Furukawa, N. and Fujiwara, M. (1999) Influence of the Difference of Postures upon the Human Physiological and Phychological Responses in a Heated Floor Room. Japanese Journal of Biometeorology, 36, 3-19.

[11] Yamato, Y., Kurazumi, Y., Fukagawa, K. and Tobita, K. (2015) Measuring Thermal Insulation Value of Clothing Using Heat Flux Sensor. The 15th Science Council of Asia Conference and International Symposium (SCA2015), Siem Reap City, 15-16 May 2015, 149-153.

[12] Yamato, Y., Kurazumi, Y., Fukagawa, K., Tobita, K. and Kondo, E. (2019) Assessment of Method for Measuring Clo Value Using Human Body, Assessment of Method for Measuring Clo Value That Assumes Human Body Temperature Adjustment. Proceedings of the 13th REHVA World Congress, Bucharest, 26-29 May 2019, 1-4. https://doi.org/10.1051/e3sconf/201911106050

[13] Seppanen, O., McNall, P.E. and Munson, D.M. (1972) Thermal Insulating for Typical Indoor Clothing Ensembles. ASHRAE Transactions, 78, 120-130.

[14] Sprague, C.H. and Munson, D.M. (1974) A Composite Ensemble Method for Estimating Thermal Insulating Values of Clothing. ASHRAE Transactions, 80, 20-129.

[15] Mihira, K. and Ohno, S. (1977) Measuring on the Clo Value of a Clothed Thermal Manikin. Journal of Home Economics of Japan, 28, 216-222.

[16] Hanada, K., Mihira, K. and Ohhata, K. (1981) Studies on the Thermal Resistance of Women's Underweares. Journal of the Japan Research Association for Textile End-Use, 22, 430-437. 
[17] Hanada, K., Mihira, K. and Sato, Y. (1983) Studies on the Thermal Resistance of Men's Underweares. Journal of the Japan Research Association for Textile End-Use, 24, 363-369.

[18] Mcllough, E.A., Jones, B.W. and Zbikowski, P.J. (1983) The Effect of Garment Design on the Thermal Insulation Values of Clothing. ASHRAE Transactions, 89, 327-353.

[19] Mcllough, E.A., Jones, B.W. and Huck, J. (1985) A Comprehensive Data Base for Estimating Clothing Insulation. ASHRAE Transactions, 91, 29-47.

[20] Olesen, B.W. (1985) A New Simpler Method for Estimating the Thermal Insulation of a Clothing Ensemble. ASHRAE Transactions, 91, 478-492.

[21] Mihira, K. and Hanada, K. (1991) A Study of Clo Values Measurement Using Thermal Manikin. Nippon Ifuku Gakkaishi, 34, 16-23.

[22] Tanabe, S., Hasebe, Y. and Tanaka, T. (1994) Reduction of Clo Value with Increased Air Velocity. Journal of Human and Living Environment, 1, 64-67.

[23] Nishimura, M., Tanabe, S. and Hasebe, Y. (1994) Effects of Skin Surface Temperature Distribution of Thermal Manikin on Clothing Thermal Insulation. Journal of Applied Human Science, 16, 181-189. https://doi.org/10.2114/jpa.16.181

[24] Sakoi, T., Mochida, T., Nagano, K. and Shimakura, K. (2000) Fundamental Study on Evaluation of Clothing Thermal Insulation. Transactions of the Society of Heating, Air-Conditioning and Sanitary Engineers of Japan, 77, 95-107.

[25] Fukazawa, T., Ikeda, S., Kim, S. and Tochihara, Y. (2009) Seasonal Clothing Variation and Thermal Resistance of Clothing Ensembles of Infants Living in Kyushu. Journal of Home Economics of Japan, 60, 635-643.

[26] ASHRAE (2017) 2017 ASHRAE Handbook Fundamentals, Chapter 8 Thermal Comfort. American Society of Heating, Refrigerating, and Air-Conditioning Engineers, Atlanta.

[27] ISO (2007) ISO 9920:2007 Ergonomics of Thermal Environment-Estimation of the Thermal Insulation and Evaporative Resistance of a Clothing Ensemble. International Organization for Standardization, Geneva.

[28] Iriki, M. (1995) Taion cyosetu no shikumi. Bunkodo Co., Ltd., Tokyo. (In Japanese)

[29] Nakayama, A. and Iriki, M. (1987) Shin seirikagaku taikei 22, Enerugi taisya Taion cyosetu no seirigaku. Igaku-Shoin Ltd., Tokyo. (In Japanese)

[30] Kurazumi, Y., Sakoi, T., Yamashita, K., Fukagawa, K., Kondo, E. and Tsuchikawa, T. (2019) Thermal Manikin of Infant. Engineering, 11, 735-754. https://doi.org/10.4236/eng.2019.1111048

[31] Meeh, K. (1879) Ober flächenmessungen des menschlichen körpers. Zeitschrift für Biologie, 15, 425-458.

[32] Lissauer, W. (1903) Ueber oberflächenmessungen un säuglingen und ihre bedeutung für den nahrungsbedarf. Jahrbuch für Kinderheilkunde und Physische Erziehung. N.F., 58, 392-411.

[33] Otani, K. (1907) Nihon syoni no taihyo menseki sokutei. Tokyo igakkai zasshi, 21, 89-117. (In Japanese)

[34] Lassabliére, P. (1910) Evaluation de la surface cutanée chez le jeune enfant. Comptes rendus hebdomadaires des séances et mémoires de la société de biologie, 59, 339-341.

[35] Klein, A.D. and Scammon, R.E. (1930) The Regional Growth in Surface Area of the Human Body in Prenatal Life. Proceedings of the Society for Experimental Biology 
and Medicine, 27, 463-466. https://doi.org/10.3181/00379727-27-4809

[36] Oshiro, C. and Tagawa, T. (1936) Nihon nyuji no taihyo menseki sokutei seiseki. Nika zasshi, 43, 604-616. (In Japanese)

[37] Ochi, T. and Higuchi, T. (1935) On the Body Surface Measurements and Normal Standard of Basal Metabolism of New Born Infants. Keio igaku, 15, 709-725. (In Japanese)

[38] Kawabata, M. (1940) Isshin taihyo menseki keisan shiki. Nihon seiri gakkai zasshi, 5, 245-254. (In Japanese)

[39] Miyajima, T. (1960) Nihon jin no taihyo menseki ni kansuru kenkyu, Dai 13 nyuji no taihyo menseki oyobi sono sansyutu shiki. Nagasaki sogo kosyu eiseigaku zasshi, 9, 484-499. (In Japanese)

[40] Tsuchikawa, T., Kondo, E. and Kurazumi, Y. (2019) Solar Radiation Area Factors of the Infant on Buggy. Journal of Human and Living Environment, 26, 87-92.

[41] Kurazumi, Y., Fukagawa, K., Sakoi, T., Naito, A., Hashimoto, R., Kondo, E. and Tsuchikawa, T. (2021) Clothing Area Factor for Typical Seasonal Clothing of Infant. Health, 13, 378-392. https://doi.org/10.4236/health.2021.134031

[42] Nihon 3B Scientific Inc. (2021) Nurse Training Baby, Asian Body Care Model Male, W17002. https://www.3bs.jp/simulator/child/w17002-w17003.htm

[43] Ministry of Health, Labour and Welfare, Japan (2021) National Growth Survey on Preschool Children. https://www.mhlw.go.jp/toukei/list/dl/73-22-01.pdf

[44] Boyd, E. and Scammon, R.E. (1930) The Relation of Surface Area Body Weight in Postnatal Life. Proceedings of the Society for Experimental Biology and Medicine, 27, 449-453. https://doi.org/10.3181/00379727-27-4804

[45] Kobayashi, O., Washio, S., Kodama, T., Sakaguchi, S. and Hayashi, I. (1952) Honpo syoni no taihyo menseki ni tuite. Nihon syonika gakkai zasshi, 56, 217-221. (In Japanese)

[46] Fujimoto, S., Watanabe, T., Sakamoto, A., Yukawa, K. and Morimoto, K. (1968) Studies on the Physical Surface Area of Japanese, Part 18 Calculation Formulas in Three Stages over All Age. Japanese Journal of Hygiene, 23, 443-450. https://doi.org/10.1265/jih.23.443

[47] Oketani, Y. and Tokura, H. (1979) Circadian Rhythms of Rectal and Skin Temperatures in an Infant. Journal of Home Economics of Japan, 30, 568-570.

[48] Whitton, J.T. and Everall, J.D. (1973) The Thickness of the Epidermis. British Journal of Dermatology, 89, 467-476.

https://doi.org/10.1111/j.1365-2133.1973.tb03007.x 